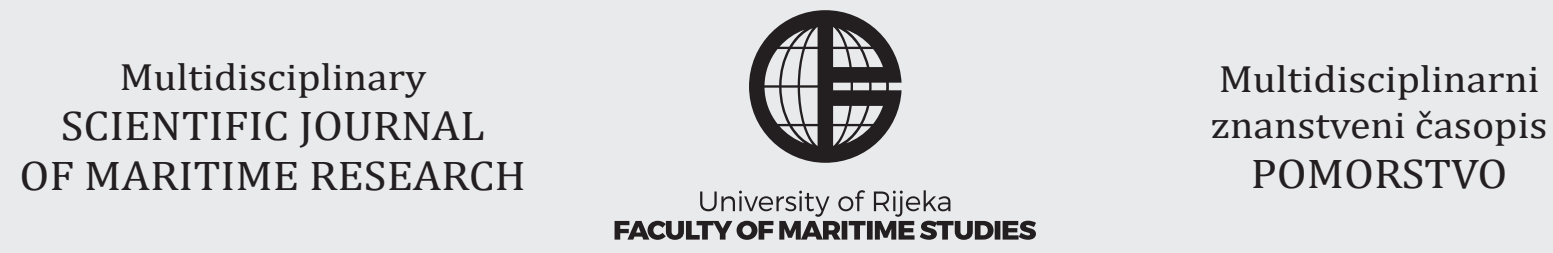

\title{
Comparison of conventional and heat balance based energy analyses of steam turbine
}

\author{
Vedran Medica-Viola, Sandi Baressi Šegota, Vedran Mrzljak, Daniel Štifanić \\ Faculty of Engineering, University of Rijeka, Vukovarska 58, 51000 Rijeka, Croatia, e-mail: vmedica@riteh.hr; sbaressisegota@riteh.hr; \\ vedran.mrzljak@riteh.hr; dstifanic@riteh.hr
}

\section{ABSTRACT}

This paper presents a comparison of conventional and heat balance based energy analyses of steam turbine. Both analyses are compared by using measured operating parameters from low power steam turbine exploitation. The major disadvantage of conventional steam turbine energy analysis is that extracted energy flow streams are not equal in real (polytropic) and ideal (isentropic) expansion processes, while the heat balance based energy analysis successfully resolved mentioned problem. Heat balance based energy analysis require an increase of steam mass flow rates extracted from the turbine in ideal (isentropic) expansion process to ensure always the same energy flow streams to all steam consumers. Increase in steam mass flow rate extracted through each turbine extraction (heat balance based energy analysis) result with a decrease in energy power losses and with an increase in energy efficiency of whole turbine and all of its cylinders (when compared to conventional analysis). All of the obtained conclusions in this research are valid not only for the analyzed low power steam turbine, but also for any other steam turbine with steam extractions.

\section{ARTICLE INFO}

Preliminary communication Received 14 February 2020

Accepted 16 March 2020

\section{Key words:}

Steam turbine

Conventional energy analysis

Heat balance based energy analysis

Turbine efficiency and losses

\section{Introduction}

In the energy sector, steam turbines are nowadays used for various functions. The most dominant steam turbines function is to drive electrical generators in various conventional $[1,2]$; nuclear $[3,4]$ or other power plants [5]. Steam turbines are also used as a constituent part of combined cycle power plants [6,7], in various marine or offshore applications [8, 9] as well as for driving various mechanical power consumers (power consumers which are not electrical generators) [10].

In the scientific and professional literature can be found many analyses of steam turbines its components or other devices which ensure stable, reliable and efficient operation of a steam turbine and the entire power plant [11]. Some of such analyses are energy analysis [12], exergy analysis [13], economy analysis [14], environmental analysis [15] and many others [16, 17]. Usually type, complexity and operational characteristics of a steam turbine or the entire plant define which analysis will be selected.
However, many researchers use a combination of mentioned analyses in order to perform complete observation of a turbine or plant from different points of view [18]. Each of mentioned analyses has advantages and disadvantages, therefore many engineers and scientists presented a propositions or methods to resolve those disadvantages. This research also utilizes an improvement method for steam turbine energy analysis.

This paper firstly presents a conventional method for steam turbine (and its cylinders) energy analysis and highlights its biggest disadvantage. Heat balance based steam turbine energy analysis method is proposed for resolving the most notable disadvantage which occurs in conventional analysis. Along with ensuring always the same energy flow stream for each steam consumer, heat balance based energy analysis of a steam turbine (and all turbine cylinders) positively influenced turbine operation. Heat balance based energy analysis of the selected steam turbine show that this method decreases turbine (and its cylinders) power losses and increases efficiencies (in 
comparison to the conventional energy analysis). Major conclusions and recommendations presented in this paper are valid not only for the observed low power steam turbine, but also for any other steam turbine which has at least one steam extraction.

\section{Description and operating parameters of the analyzed steam turbine}

Analyzed turbine is a low power steam turbine (its nominal power equals $35 \mathrm{MW}$ ) which operates in solar thermal power plant [19]. Like many other steam turbines from the literature $[20,21]$, analyzed turbine consists of two cylinders (HPC - High Pressure Cylinder and LPC Low Pressure Cylinder) mounted on the same shaft which drives an electrical generator, Fig. 1.

Steam delivered from the steam generator [22, 23] expands firstly through the HPC. HPC has two steam extractions; both of them delivered a certain amount of steam to high pressure feed water heaters [24, 25]. After expansion in HPC, remaining steam mass flow rate is delivered to steam re-heater. In steam re-heater, additional fuel is used in order to increase the steam temperature before its expansion in LPC. Increasing of steam temperature before expansion in LPC resulted with a fact that the last LPC stages operate with lower amount of water droplets (higher steam content) what positively influenced on its operation (high amount of water droplets increases erosion of the turbine blades, requires more rigorous maintenance and causes non-optimal flow though stator and rotor turbine blades) [26, 27]. Therefore, the influence of re-heater is resolving of many problems which can be expected during operation with wet steam [28]. Furthermore, it should be noted that the re-heater can be an independent component in steam power plant, or more often, it is an integral part of steam generator [29, 30].

After the steam temperature increase in re-heater, steam further expands in LPC, Fig. 1. LPC has three steam extractions - first of them delivers a certain amount of steam into deaerator [31], while the second and third extraction delivers a certain amount of steam into the low pressure condensate heaters [32, 33]. Remaining steam mass flow rate, after expansion in LPC, is delivered to the main steam condenser for condensation (changing of aggregate state) [34, 35].

As in [19], also in this analysis is adopted that mechanical losses in both turbine cylinders (and consequentially in each turbine stage) as well as mechanical losses during power transmission to electrical generator were not taken into consideration (they are equal to zero). Also, the steam mass flow rate leaked through each gland seal (front and rear) of each turbine cylinder is neglected (due to its relatively low influence on the whole turbine operation and energy analysis).

In Fig. 1 are also presented operating points of the analyzed steam turbine (from 1 to 9) required for conventional and heat balance based energy analysis.

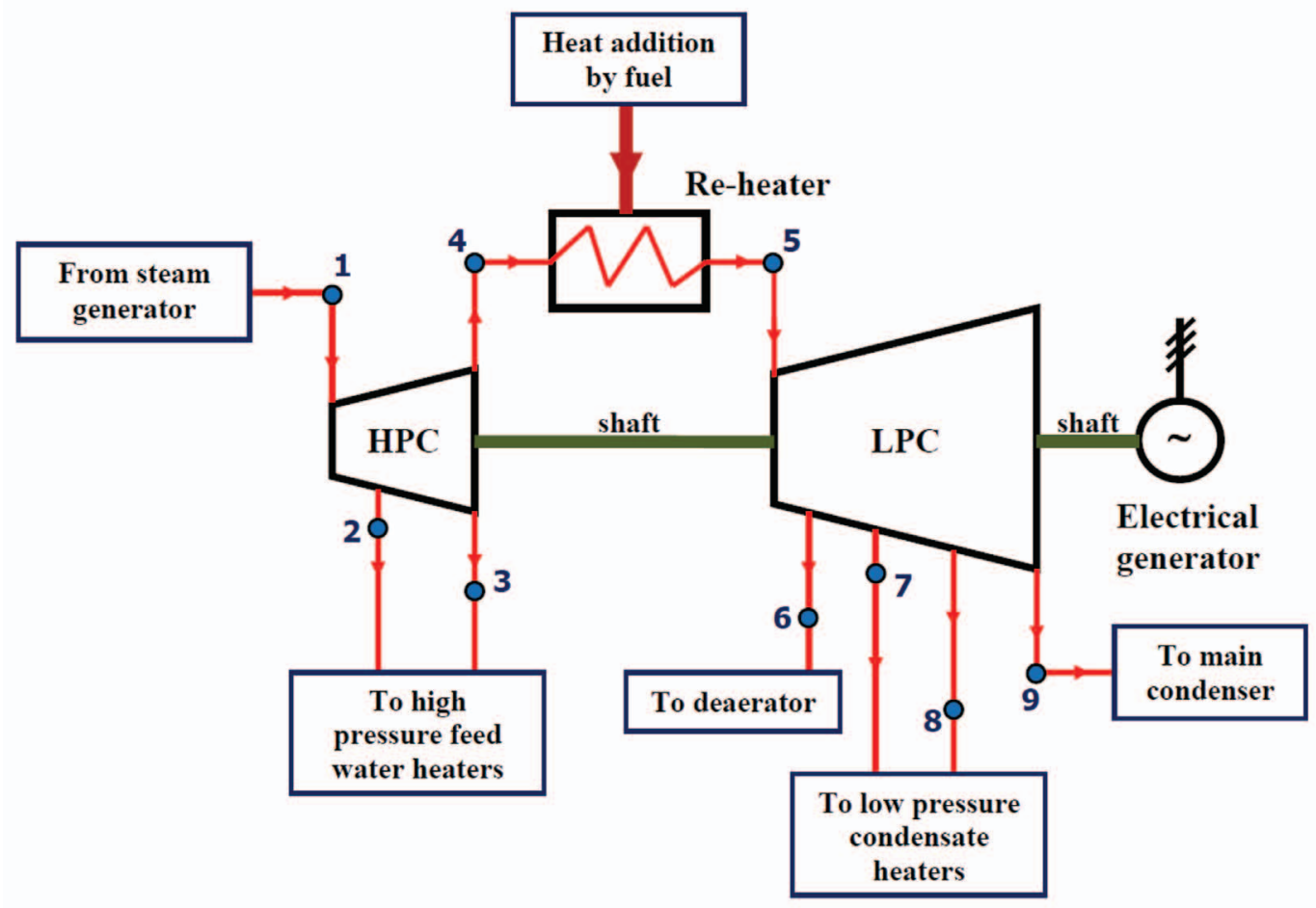

Fig. 1 Scheme and required operating points for the energy analysis of observed steam turbine (nominal power 35 MW) 
Steam operating parameters (steam temperature, pressure and mass flow rate) in each operating point from Fig. 1 , related to real (polytropic) steam expansion process, are found in [19] and presented in Table 1.

Steam specific enthalpies, specific entropies and steam quality in each operating point from Fig. 1 are calculated from known steam pressure and temperature by using NIST REFPROP 9.0 software [36]. Only for the last operating point (operating point 9, Fig. 1) other steam properties are calculated from known steam pressure and quality. Steam quality is steam content, so when steam quality is equal to 0.95 (operating point 9 , Table 1), in that operating point steam has $95 \%$ of gas phase and $5 \%$ of water droplets. At the condenser inlet (LPC outlet) steam must be under the saturation line (where water droplets in gas phase occur) to allow condensation [37].

It should be noted that during real (polytropic) expansion process as well as during re-heating, steam specific entropy continuously increases [38, 39]. When observing differences between each two operating points of the analyzed steam turbine, from Table 1 can be easily noted that the highest increase in steam specific entropy occur during heat addition in re-heater.

Real (polytropic) and ideal (isentropic) steam expansion processes inside each analyzed steam turbine cylinder are presented in $h$-s diagram, Fig. 2 (according to

Table 1 Steam operating parameters for the real (polytropic) expansion process [19]

\begin{tabular}{|c|c|c|c|c|c|c|}
\hline 0. P.* & $\begin{array}{c}\text { Temperature } \\
\left({ }^{\circ} \mathbf{C}\right)\end{array}$ & $\begin{array}{c}\text { Pressure } \\
\text { (bar) }\end{array}$ & $\begin{array}{c}\text { Mass flow rate } \\
\mathbf{( k g} / \mathbf{s})\end{array}$ & $\begin{array}{c}\text { Specific enthalpy } \\
(\mathbf{k J} / \mathbf{k g})\end{array}$ & $\begin{array}{c}\text { Specific entropy } \\
(\mathbf{k J} / \mathbf{k g} \cdot \mathbf{K})\end{array}$ & Quality \\
\hline 1 & 370.00 & 102.00 & 39.546 & 2993.3 & 6.0481 & Superheated \\
\hline 2 & 244.10 & 34.27 & 2.617 & 2813.0 & 6.1526 & Superheated \\
\hline 3 & 215.00 & 20.50 & 3.069 & 2803.2 & 6.3389 & Superheated \\
\hline 4 & 215.00 & 20.50 & 33.860 & 2803.2 & 6.3389 & Superheated \\
\hline 5 & 370.00 & 18.45 & 33.860 & 3185.0 & 7.0692 & Superheated \\
\hline 6 & 269.46 & 8.10 & 2.893 & 2991.8 & 7.1122 & Superheated \\
\hline 7 & 132.70 & 2.00 & 2.477 & 2733.0 & 7.1939 & Superheated \\
\hline 8 & 78.19 & 0.44 & 1.375 & 2640.0 & 7.6388 & Superheated \\
\hline 9 & 41.51 & 0.08 & 27.115 & 2456.1 & 7.8456 & 0.95 \\
\hline
\end{tabular}

*O. P. = Operating point (refers to Fig. 1)

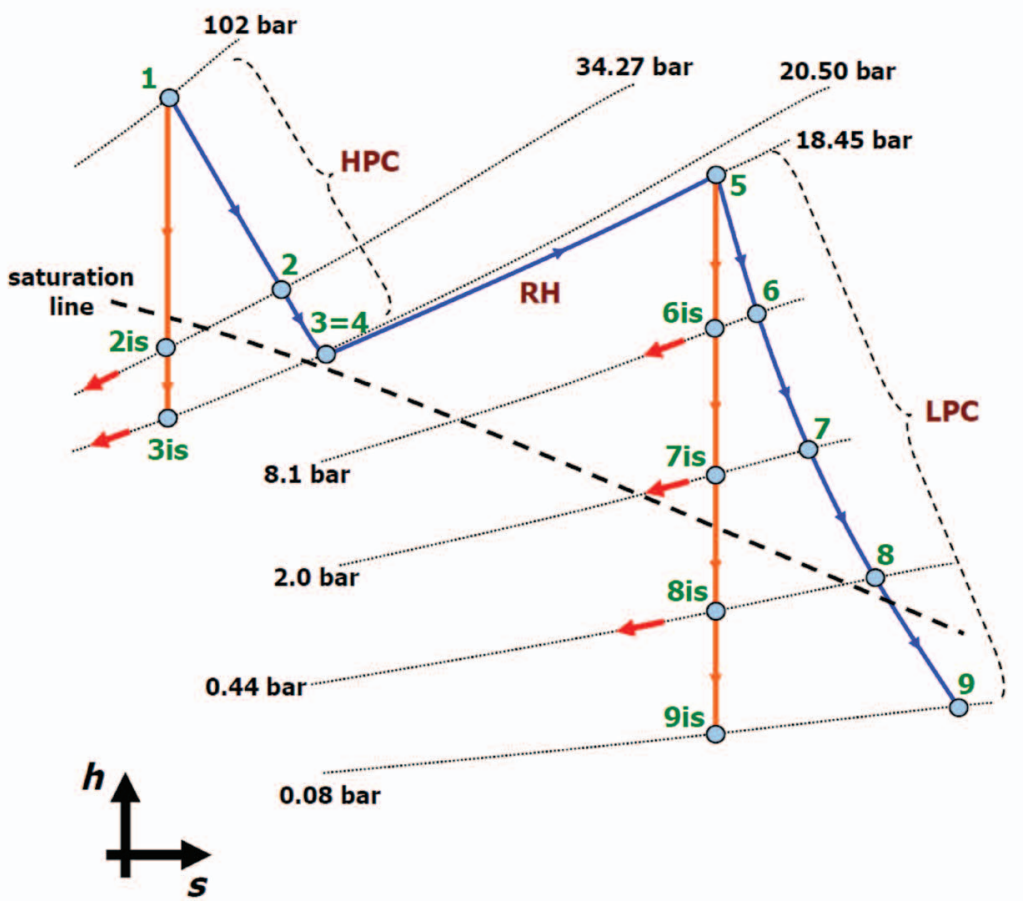

Fig. 2 Steam expansion processes (real - blue curves; ideal - orange lines) in $h$-s diagram for the analyzed steam turbine 
data from Table 1). Increase of steam temperature inside re-heater (RH) is also clearly visible in Fig. 2 along with the fact that due to losses steam pressure inside re-heater slightly decreases (from 20.50 bars at the re-heater inlet to 18.45 bars at the re-heater outlet, Table 1 ).

Ideal (isentropic) steam expansion process (points marked with - is) assumes always the same steam specific entropy, from the each turbine cylinder inlet until the outlet [40, 41]. Red arrows in Fig. 2 represent steam extractions from each turbine cylinder. Steam mass flow rates of each extraction, from each cylinder, are presented in Table 1.

Energy analysis of each turbine cylinder (and consequentially the whole turbine) is based on the comparison of real (polytropic) and ideal (isentropic) steam expansion processes $[42,43]$. Power developed in each turbine cylinder and the whole turbine will always be higher according to ideal than real expansion process (due to neglecting losses during steam expansion in ideal process). However, conventional steam turbine energy analysis does not take into account one specific fact, which will be discussed and corrected in heat balance based energy analysis of the same steam turbine.

Ideal (isentropic) steam expansion process is the process between the same pressures as in the real (polytropic) expansion, but with the same specific entropies from the expansion beginning until its end in each cylinder. So, steam specific entropies for the complete ideal (isentropic) process in each turbine cylinder are equal as steam specific entropies at the beginning of expansion in real (polytropic) process for each cylinder. From known steam pressures and specific entropies at the inlet of each turbine cylinder, Fig. 2, are calculated steam specific enthalpies in ideal expansion process (by using NIST REFPROP 9.0 software [36]) and presented in Table 2 .

Table 2 Steam specific enthalpies for the ideal (isentropic) expansion process

\begin{tabular}{|c|c|c|c|}
\hline 0. P.* & $\begin{array}{c}\text { Pressure } \\
\text { (bar) }\end{array}$ & $\begin{array}{c}\text { Specific entropy } \\
\text { (kJ/kg·K) }\end{array}$ & $\begin{array}{c}\text { Specific enthalpy- } \\
\text { isentropic } \\
\text { (kJ/kg) }\end{array}$ \\
\hline 1 & 102.00 & 6.0481 & 2993.3 \\
\hline 2is & 34.27 & 6.0481 & 2759.2 \\
\hline 3is & 20.50 & 6.0481 & 2661.6 \\
\hline 5 & 18.45 & 7.0692 & 3185.0 \\
\hline 6is & 8.10 & 7.0692 & 2968.7 \\
\hline 7is & 2.00 & 7.0692 & 2683.5 \\
\hline 8is & 0.44 & 7.0692 & 2440.0 \\
\hline 9is & 0.08 & 7.0692 & 2211.8 \\
\hline
\end{tabular}

*O. P. = Operating point (refers to Fig. 2 )

Source: Authors

\section{Energy analysis}

\subsection{Energy analysis of any control volume or a system}

The first law of thermodynamics defines energy analysis of any system or a control volume [44]. The complete energy balance equation for any system or a control volume is [45]:

$$
\begin{aligned}
& \dot{Q_{N}}+P_{N}+\sum\left(\dot{m_{N}} \cdot\left(h_{N}+\frac{c_{N}^{2}}{2}+g \cdot z_{N}\right)\right)= \\
& \dot{Q_{\text {OUT }}}+P_{\text {OUT }}+\sum\left(\dot{m_{\text {OUT }}} \cdot\left(h_{\text {OUT }}+\frac{c_{\text {OUT }}^{2}}{2}+g \cdot z_{\text {OUT }}\right)\right)
\end{aligned}
$$

where $\dot{Q}$ in $(\mathrm{kW})$ is energy heat transfer, $P$ in $(\mathrm{kW})$ is power, $\dot{m}$ in $(\mathrm{kg} / \mathrm{s})$ is operating medium mass flow rate, $h$ in $(\mathrm{kJ} / \mathrm{kg})$ is operating medium specific enthalpy, $c$ in $(\mathrm{m} / \mathrm{s})$ is operating medium velocity, $g$ in $\left(\mathrm{m} / \mathrm{s}^{2}\right)$ is acceleration of gravity and $z$ in $(\mathrm{m})$ is elevation on which operating medium currently exist. Index IN is related to the inlet (input), while index OUT is related to the outlet (output).

In the majority of cases, the complete energy balance equation can be simplified because potential and kinetic energies can be disregarded [46], so the simplified energy balance equation is [47]:

$$
Q_{N}^{\dot{P}}+P_{N}+\sum E \dot{n}_{N}=Q_{\text {OUT }}^{\dot{P}}+P_{\text {OUT }}+\sum E \dot{n}_{\text {OUT }}
$$

where $E \dot{n}$ is a total energy of operating medium flow defined according to $[48,49]$ by an equation:

$$
\dot{E n}=\dot{m} \cdot h .
$$

The energy efficiency of any system or a control volume in general form can be defined as presented in [50]:

$$
\eta_{e n}=\frac{\text { cumulative energy output }}{\text { cumulative energy input }} .
$$

During the energy analysis of any system or a control volume usually is not observed operating medium mass flow rate leakage. Therefore, in the majority of cases, mass flow rate balance is also valid [51]:

$$
\sum \dot{m}_{N}=\sum \dot{m}_{\text {OUT }} .
$$

Presented general equations are the baseline for energy analysis of any system or a control volume, so they also must be satisfied in the energy analysis of observed steam turbine and both of its cylinders, regardless of used energy analysis method.

\subsection{Conventional energy analysis of the observed steam turbine}

Conventional energy analysis of a steam turbine and all of its cylinders is based on the comparison of real (polytropic) and ideal (isentropic) steam expansion processes with a note that the steam mass flow rate extracted from 
each turbine cylinder at each extraction remains the same for both ideal and real processes [52].

In this section are presented equations for the conventional energy analysis of the whole observed steam turbine and both of its cylinders. Operating points in all of the equations are related to Fig. 2 .

\section{HPC conventional energy analysis}

- Real (polytropic) produced power:

$$
P_{r e, H P C}=\dot{m}_{1} \cdot\left(h_{1}-h_{2}\right)+\left(\dot{m}_{1}-\dot{m}_{2}\right) \cdot\left(h_{2}-h_{3}\right) \text {. }
$$

- Ideal (isentropic) power:

$$
P_{i d, H P C}=\dot{m}_{1} \cdot\left(h_{1}-h_{2 i s}\right)+\left(\dot{m}_{1}-\dot{m}_{2}\right) \cdot\left(h_{2 i s}-h_{3 i s}\right) .
$$

- Energy power loss:

$$
\dot{E}_{\text {loss, } H P C}=P_{i d, H P C}-P_{r e, H P C} .
$$

- Energy efficiency:

$$
\eta_{e n, H P C}=\frac{P_{r e, H P C}}{P_{i d, H P C}} .
$$

- Mass flow rate balance:

$$
\begin{aligned}
& \dot{m}_{4}=\dot{m}_{1}-\dot{m}_{2}-\dot{m}_{3}, \\
& \dot{m}_{4}=\dot{m}_{5} .
\end{aligned}
$$

\section{LPC conventional energy analysis}

- Real (polytropic) produced power:

$$
\begin{aligned}
P_{r e, L P C}= & \dot{m}_{5} \cdot\left(h_{5}-h_{6}\right)+\left(\dot{m}_{5}-\dot{m}_{6}\right) \cdot\left(h_{6}-h_{7}\right)+ \\
& +\left(\dot{m}_{5}-\dot{m}_{6}-\dot{m}_{7}\right) \cdot\left(h_{7}-h_{8}\right)+ \\
& +\left(\dot{m}_{5}-\dot{m}_{6}-\dot{m}_{7}-\dot{m}_{8}\right) \cdot\left(h_{8}-h_{9}\right) .
\end{aligned}
$$

- Ideal (isentropic) power:

$$
\begin{aligned}
& P_{i d, L P C}=\dot{m}_{5} \cdot\left(h_{5}-h_{6 i s}\right)+\left(\dot{m}_{5}-\dot{m}_{6}\right) \cdot\left(h_{6 i s}-h_{7 i s}\right)+ \\
& +\left(\dot{m}_{5}-\dot{m}_{6}-\dot{m}_{7}\right) \cdot\left(h_{7 i s}-h_{8 i s}\right)+ \\
& +\left(\dot{m}_{5}-\dot{m}_{6}-\dot{m}_{7}-\dot{m}_{8}\right) \cdot\left(h_{8 i s}-h_{9 i s}\right) .
\end{aligned}
$$

- Energy power loss:

$$
\dot{E}_{l o s s, L P C}=P_{i d, L P C}-P_{r e, L P C} \text {. }
$$

- Energy efficiency:

$$
\eta_{e n, L P C}=\frac{P_{r e, L P C}}{P_{i d, L P C}} .
$$

- Mass flow rate balance:

$$
\dot{m}_{9}=\dot{m}_{5}-\dot{m}_{6}-\dot{m}_{7}-\dot{m}_{8}
$$

\section{Whole Turbine (WT) conventional energy analysis}

- Real (polytropic) produced power:

$$
P_{r e, W T}=P_{r e, H P C}+P_{r e, L P C} .
$$

- Ideal (isentropic) power:

$$
P_{i d, W T}=P_{i d, H P C}+P_{i d, L P C} .
$$

- Energy power loss:

$$
\dot{E}_{l o s s, W T}=P_{i d, W T}-P_{r e, W T}=\dot{E}_{l o s s, H P C}+\dot{E}_{l o s s, L P C} .
$$

- Energy efficiency:

$$
\eta_{e n, W T}=\frac{P_{r e, W T}}{P_{i d, W T}} .
$$

\subsection{Heat balance based energy analysis of the observed steam turbine}

Heat balance based energy analysis of a steam turbine and all of its cylinders is also based on the comparison of real (polytropic) and ideal (isentropic) steam expansion processes with a note that the steam mass flow rate extracted from each turbine cylinder at each extraction did not remain the same for both ideal and real processes.

In conventional energy analysis of a steam turbine, the same steam mass flow rate extracted from any turbine cylinder at each extraction in real and the ideal expansion process resulted with a fact that steam consumers (feed water heaters, deaerator, condensate heaters or others) will not get the same energy flow stream from the turbine.

For the analyzed steam turbine from Fig. 2 can be seen that ideal steam expansion process at the steam extraction points has a lower specific enthalpies than the real expansion process. For example, at first steam extraction from HPC - operating point 2is has a lower specific enthalpy than operating point 2 or at the last steam extraction from LPC - operating point 8is has a lower specific enthalpy than operating point 8 .

Heat balance based energy analysis of the steam turbine is based on the change of steam mass flow rates for ideal (isentropic) steam expansion process with an aim that each steam consumer, in each extraction, gets the same steam energy flow stream as in real process. All the equations for the heat balance based energy analysis of a steam turbine are identical as for the conventional energy analysis, while the extracted steam mass flow rates for the ideal process will be calculated again to ensure heat balance for all steam consumers.

In the real (polytropic) steam expansion process, steam mass flow rates extracted from the turbine remain the same as in the conventional energy analysis (Table 1), so in both conventional and heat balance based energy analysis real expansion process (and its parameters) remains the same. Steam energy flow stream in each turbine 
or cylinder extraction for the real expansion process is calculated according to Eq. 3. Therefore, steam energy flow streams for each turbine extraction in the real (polytropic) process (according to Fig. 2), are:

$$
\begin{aligned}
& \dot{E} n_{r e, 2}=\dot{m}_{2} \cdot h_{2}, \\
& \dot{E} n_{r e, 3}=\dot{m}_{3} \cdot h_{3}, \\
& \dot{E} n_{r e, 6}=\dot{m}_{6} \cdot h_{6}, \\
& \dot{E} n_{r e, 7}=\dot{m}_{7} \cdot h_{7}, \\
& \dot{E} n_{r e, 8}=\dot{m}_{8} \cdot h_{8} .
\end{aligned}
$$

To ensure heat balance for all steam consumers (to ensure identical steam energy flow streams extracted in the real and ideal expansion processes), extracted steam mass flow rates for the ideal (isentropic) expansion process will be calculated by using an equation:

$$
\dot{m}_{N}=\frac{\dot{E} n_{r e, N}}{h_{N i s}},
$$

where index $\mathrm{N}$ denotes each extraction point (according to Fig. 1).

Change in steam mass flow rates extracted from the turbine and both of its cylinders in ideal process (to ensure heat balance of all steam consumers) will result with a change in mass flow rate balances of HPC and LPC (equations for the mass flow rate balances of both turbine cylinders remains the same in heat balance based as in conventional analysis, the change occurs only in the values of steam mass flow rates).

It will be interesting to present how retaining of steam consumers heat balance in both real and ideal expansion processes influenced steam turbine and both of its cylinders energy power loss and energy efficiency (when compared to conventional energy analysis). It should be highlighted that presented equations and principles of heat balance based energy analysis are valid not only for the observed steam turbine, but also for any other steam turbine (or turbine cylinder) which has at least one steam extraction.

\section{Results and discussion}

\subsection{Results of conventional energy analysis for the observed steam turbine}

In conventional energy analysis of the observed steam turbine and its cylinders (as well as in conventional energy analysis of any other steam turbine or turbine cylinder), real (polytropic) developed power is lower in comparison with ideal (isentropic) power due to losses in steam expansion process which are taken into account only in real process, while in the ideal process they are neglected. However, ideal power represents maximal power potential which can be developed (in the ideal case) in each turbine cylinder or in the whole turbine.

From Fig. 3 can clearly be seen that for the observed turbine the majority of power is developed in LPC, regardless of the expansion process. LPC real (polytropic) developed power is approximately three times higher in comparison with HPC real power (similar ratio is valid for ideal power). From the viewpoint of steam mass flow rates, this conclusion is quite interesting, because through HPC expanded higher steam mass flow rate than through LPC, while additionally, cumulative steam mass flow rate extracted through both HPC extractions is lower than cumulative steam mass flow rate extracted through three LPC extractions, Table 1 . The reason why the LPC produces much higher power than HPC can be seen in Fig. 2 specific heat drop (specific enthalpy difference) of the LPC is much higher than specific heat drop of HPC.

The sum of real or ideal power in both turbine cylinders resulted with cumulative power of the whole analyzed steam turbine. According to steam operating parameters presented in Table 1, real produced power inside the whole turbine equals $29684.08 \mathrm{~kW}$, while ideal power, which can be developed in the best possible case, for the observed turbine is equal to $42142.65 \mathrm{~kW}$. As mentioned before, nominal power of the analyzed steam turbine is $35 \mathrm{MW}$ so the steam operating parameters presented in Table 1 refer to turbine operation at approximately $85 \%$ of nominal power.

The results of the conventional energy analysis for the observed steam turbine and both its cylinders show that LPC has a higher energy power loss in comparison to HPC (the difference is $1718.69 \mathrm{~kW}$ ) what can be expected due to much higher power (real and ideal) developed in LPC, Fig. 4. For the observed steam turbine cylinders, energy power loss and energy efficiency are directly proportional, so the LPC which has higher energy power loss also has higher energy efficiency in comparison to HPC (LPC energy efficiency is $17.54 \%$ higher than energy efficiency of the HPC).

The whole observed turbine, according to conventional energy analysis, has energy power loss equal to 12458.58 $\mathrm{kW}$ and energy efficiency equal to $70.44 \%$, Fig. 4 , what is the expected energy efficiency for such low power steam turbine [53].

The biggest disadvantages of the conventional energy analysis are different steam energy flow streams delivered from steam turbine to each heat consumer in the real and ideal expansion processes (the same extracted steam mass flow rates with different steam specific enthalpies). As noted before, steam specific enthalpies of ideal (isentropic) expansion process for each extraction are lower in comparison to real (polytropic) expansion process, what resulted with a fact that for each extraction steam energy flow stream extracted from the turbine is 


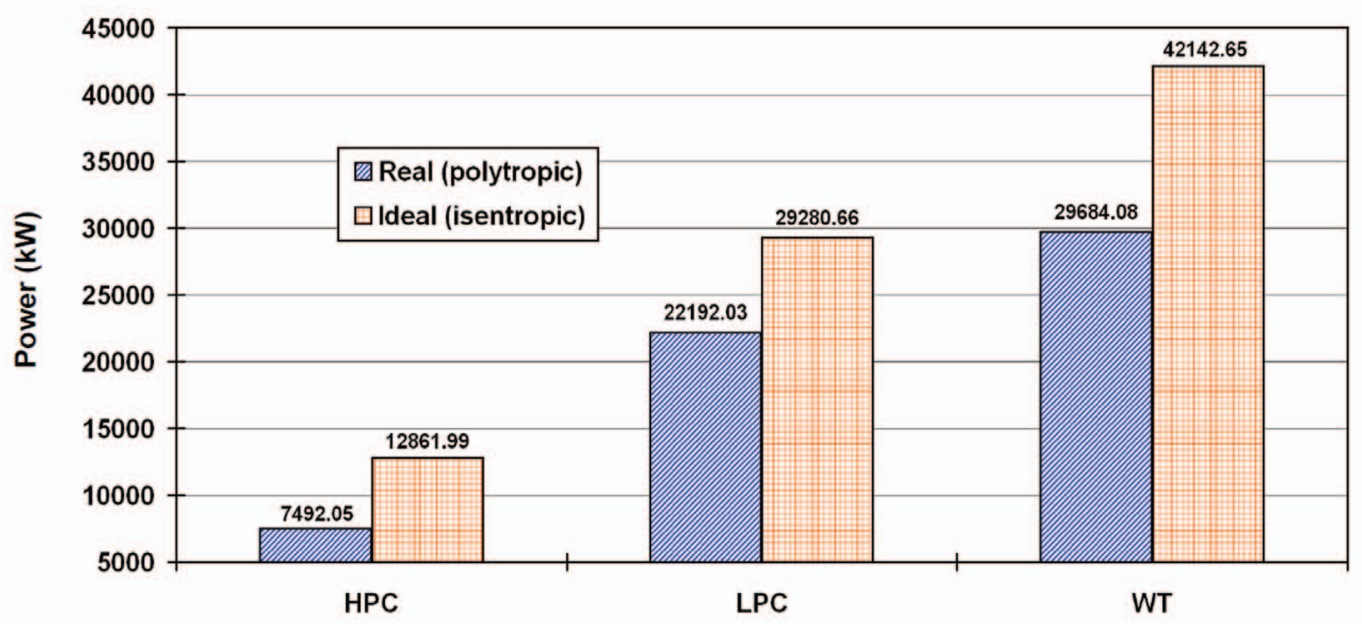

Fig. 3 Real (polytropic) and ideal (isentropic) power of the whole analyzed steam turbine and both of its cylinders - conventional energy analysis

Source: Authors

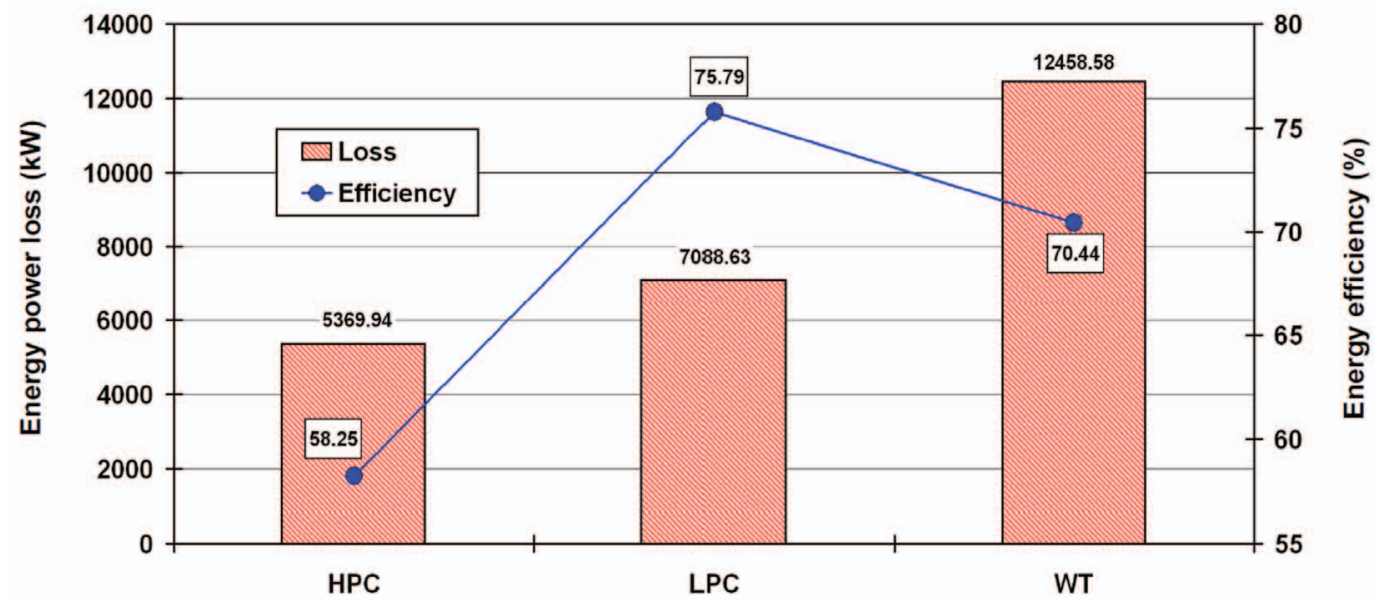

Fig. 4 Energy power loss and energy efficiency of the whole analyzed steam turbine and both of its cylinders - conventional energy analysis

Source: Authors

lower in ideal than in the real expansion process, Fig. 5. From the viewpoint of steam consumers, those extracted steam energy flow streams should be equal to ensure stable and proper operation of each steam consumer. This fact is neglected in conventional energy analysis, but it must be taken into account during the heat balance based energy analysis of the observed (or any other) steam turbine.

From Fig. 5 can be seen that the differences in extracted steam energy flow streams between real and ideal expansion processes are mostly small, but in some extractions they can be notable (as for example at the last extraction from HPC - operating points 3 and 3is as well as at the last extraction from LPC - operating points 8 and 8is).
Furthermore, Fig. 5 shows that the highest steam energy flow stream extracted from the observed turbine is at the first LPC extraction (operating points 6 and 6is), followed by the second HPC extraction (operating points 3 and 3is), while the lowest steam energy flow stream extracted from the observed turbine is at the third LPC extraction (operating points 8 and 8 is).

From the above observations can be concluded that steam energy flow streams extracted at each turbine extraction can significantly differ (between each other), while in some turbine extractions the difference between extracted steam energy flow streams in real and ideal expansion processes can be notable for conventional energy analysis. 


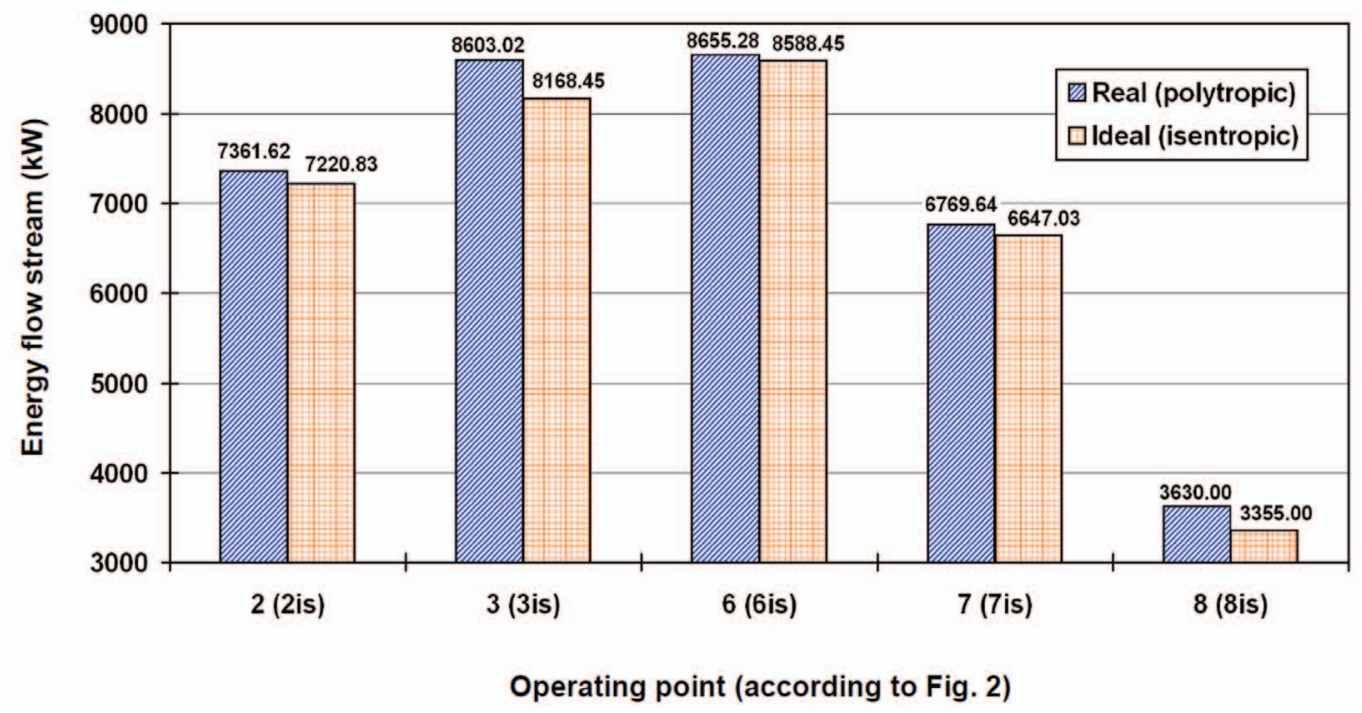

Fig. 5 Energy flow streams extracted from the analyzed steam turbine in real (polytropic) and ideal (isentropic) steam expansion processes - conventional energy analysis

Source: Authors

\subsection{Differences between conventional and heat balance based energy analyses of the observed steam turbine}

The difference in steam mass flow rate for ideal (isentropic) steam expansion process between conventional and heat balance based energy analyses of the observed steam turbine are presented in Fig. 6. Results presented in Fig. 6 (in each extraction point) are strongly related to energy flow streams presented in Fig. 5.

At the HPC inlet, the steam mass flow rate is equal in conventional and heat balance based energy analysis. In order to retain the same energy flow stream at the first HPC extraction, mass flow rate for the ideal (isentropic) process (operating point 2is) must be increased for 0.051 $\mathrm{kg} / \mathrm{s}$, while for the second HPC extraction (operating point 3is) mass flow rate must be increased for $0.163 \mathrm{~kg} / \mathrm{s}$. It can be noted that an increase in the steam mass flow rate of ideal (isentropic) process, with an aim to retain heat balance, is much higher for the second than for the first HPC extraction. The reason of such occurrence can be found in Fig. 5 - energy flow stream extracted in the ideal process at second HPC extraction has much higher difference (when compared to real process) than energy flow stream extracted at first HPC extraction, therefore in the second HPC extraction is required higher mass flow rate to compensate such difference.

Operating points 4 and 5, Fig. 6, are not related to ideal (isentropic) steam expansion process in any observed steam turbine cylinder, but the mass flow rate balance, Eq. 10 , must be satisfied also in this case. As in each HPC extraction is removed higher steam mass flow rate (to retain the heat balance for steam consumers), remaining steam mass flow rate at the HPC outlet will be lower. Therefore, in con- ventional energy analysis, steam mass flow rate at the HPC outlet will be higher for $0.214 \mathrm{~kg} / \mathrm{s}$ in comparison to heat balance based energy analysis. The steam mass flow rate remains unchanged between re-heater inlet and outlet.

In heat balance based energy analysis, steam mass flow rate extracted from each LPC extraction is higher in comparison to the conventional energy analysis. Change in mass flow rate extracted at each LPC extraction is proportional to the difference in energy flow streams, Fig. 5 - higher difference in energy flow streams (for each extraction point) resulted with higher steam mass flow rate extracted in heat balance based energy analysis. Therefore, in heat balance based energy analysis of observed LPC, extracted steam mass flow rate will be higher in comparison to conventional analysis: at first extraction (operating point 6is) for $0.023 \mathrm{~kg} / \mathrm{s}$, at second extraction (operating point $7 \mathrm{is}$ ) for $0.046 \mathrm{~kg} / \mathrm{s}$ and at third extraction (operating point 8is) for $0.113 \mathrm{~kg} / \mathrm{s}$.

Due to higher steam mass flow rates extracted through all observed steam turbine extractions (both in HPC and LPC) during the heat balance based energy analysis, remaining steam mass flow rate, Eq. 16, which will be delivered to the main steam condenser is higher in conventional than in heat balance based energy analysis for $0.395 \mathrm{~kg} / \mathrm{s}$.

The differences in energy power loss and energy efficiency between conventional and heat balance based energy analysis of the observed steam turbine are presented in Fig. 7. From Fig. 7 can be derived several important conclusions.

In comparison to the conventional energy analysis, heat balance based energy analysis of observed steam turbine decrease energy power loss and increases energy efficiency of each turbine cylinder and the whole turbine. 


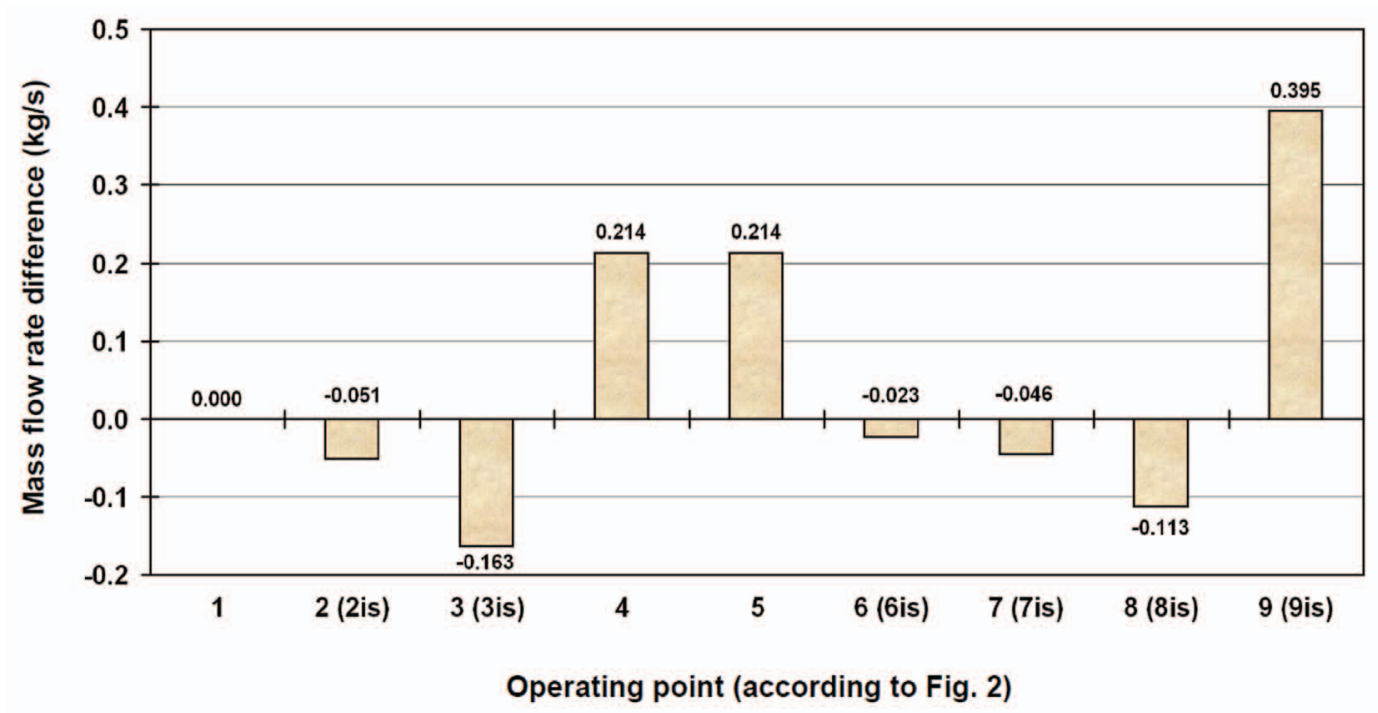

Fig. 6 The mass flow rate difference between conventional and heat balance based energy analyses for ideal expansion process in each operating point of the observed steam turbine

Source: Authors

Furthermore, the difference between conventional and heat balance based energy analysis (in energy power loss and energy efficiency) for HPC is almost negligible, while for LPC and the whole turbine that difference is clearly visible, Fig. 7.

Heat balance based energy analysis in comparison to conventional analysis decreases LPC energy power loss for $272.87 \mathrm{~kW}$ and increases LPC energy efficiency for $0.71 \%$, while for the whole turbine heat balance based energy analysis decreases energy power loss for $277.85 \mathrm{~kW}$ and increases energy efficiency for $0.47 \%$.
The most important conclusion of the presented analysis, derived from Fig. 7, is that increase in the steam mass flow rate extracted through each steam turbine extraction, resulted with a decrease in energy power losses and with an increase in energy efficiency of whole analyzed turbine and all of its cylinders. This conclusion is not only valid for the observed, but also for any other steam turbine (this fact is based on additional conventional and heat balance based energy analyses performed on several other complex steam turbines with many cylinders and steam extractions).

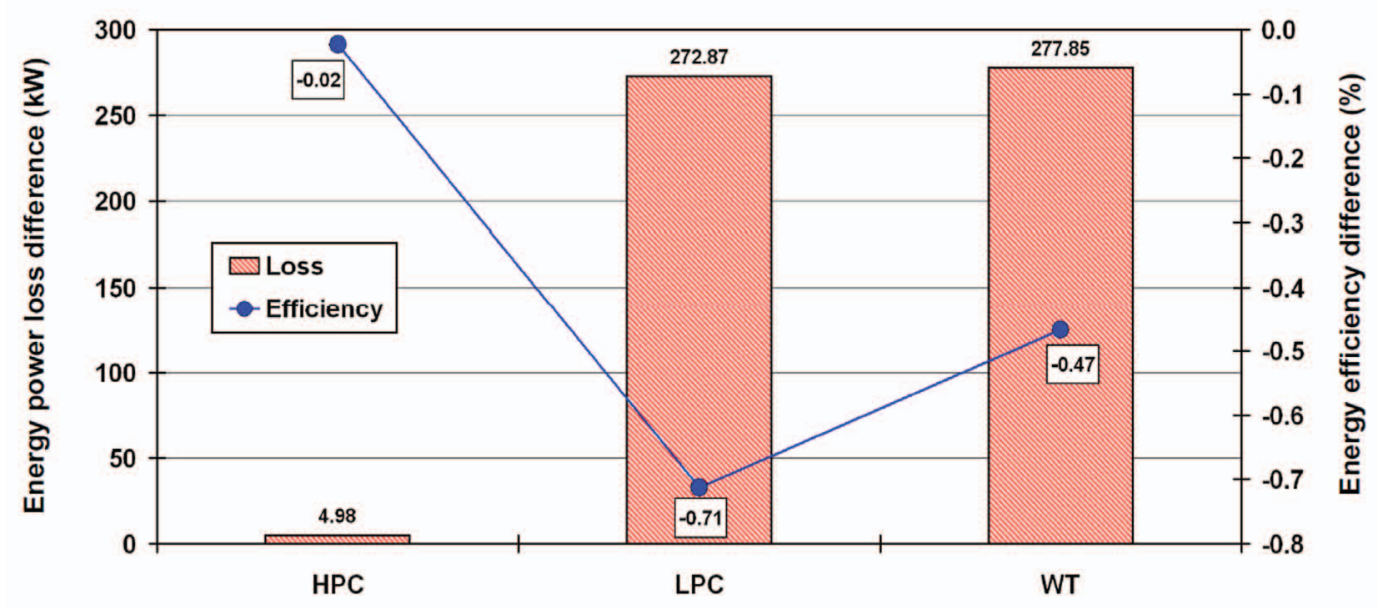

Fig. 7 Energy power loss and energy efficiency difference between conventional and heat balance based energy analyses for the whole observed steam turbine and both of its cylinders 


\section{Conclusions}

In this paper is presented a comparison of conventional and heat balance based energy analyses of low power steam turbine which operates in solar thermal power plant. Heat balance based energy analysis takes into account the fact that all of the steam consumers always get the same energy flow stream from the observed steam turbine (what conventional energy analysis did not take into account). The complete analysis presented in this paper is based on the steam operating parameters measured during the turbine exploitation. The most important conclusions of the presented comparison are:

- Conventional energy analysis shows that the LPC is the dominant power producer (when compared to HPC) and LPC develops approximately three times higher real (polytropic) power in comparison with HPC.

- Conventional energy analysis also shows that for the observed steam turbine cylinders developed power, energy power loss and energy efficiency are direct proportional - cylinder which develop higher power will have a higher energy power loss and simultaneously higher energy efficiency.

- The major disadvantage of conventional energy analysis is that energy flow streams extracted from the steam turbine are not equal in real (polytropic) and ideal (isentropic) expansion processes (in each extraction, mass flow rates are equal, but steam specific enthalpies are lower for ideal expansion process).

- Heat balance based energy analysis ensures always the same energy flow stream to any steam consumer, regardless of steam expansion process.

- Heat balance based energy analysis requires increase of steam mass flow rate extracted through each turbine extraction, what also changes other steam mass flow rates through the turbine (mass flow rate balances must always be satisfied).

- Increase in steam mass flow rate extracted through each turbine extraction resulted with a decrease in energy power losses and with an increase in energy efficiencies of whole turbine and all of its cylinders. Therefore, heat balance based energy analysis of steam turbine and its cylinders will result with lower energy power losses and with higher energy efficiencies in comparison to conventional analysis.

- All of the conclusions and principles presented in this paper about conventional and heat balance based energy analyses are valid not only for the observed, but also for any other steam turbine or turbine cylinder which has at least one steam extraction.

\section{Acknowledgments}

This research has been supported by the Croatian Science Foundation under the project IP-2018-01-3739, CEEPUS network CIII-HR-0108, European Regional
Development Fund under the grant KK.01.1.1.01.0009 (DATACROSS), University of Rijeka scientific grant uniritehnic-18-275-1447 and University of Rijeka scientific grant uniri-tehnic-18-18-1146.

\section{References}

[1] Zhang, Y., Wang, J., Yang, S., Gao, W.: An all-condition simulation model of the steam turbine system for a $600 \mathrm{MW}$ generation unit, Journal of the Energy Institute 91 (2), p. 279-288, 2018. (doi:10.1016/j.joei.2016.11.007)

[2] Elhelw, M., Al Dahma, K. S., Hamid Attia, A. E.: Utilizing exergy analysis in studying the performance of steam power plant at two different operation mode, Applied Thermal Engineering 150 , p. 285-293, 2019. (doi:10.1016/j.applthermaleng.2019.01.003)

[3] Naserbegi, A., Aghaie, M., Minuchehr, A., Alahyarizadeh, Gh.: A novel exergy optimization of Bushehr nuclear power plant by gravitational search algorithm (GSA), Energy 148, p. 373385, 2018. (doi:10.1016/j.energy.2018.01.119)

[4] Wang, C., Yan, C., Wang, J., Tian, C., Yu, S.: Parametric optimization of steam cycle in PWR nuclear power plant using improved genetic-simplex algorithm, Applied Thermal Engineering 125, p. 830-845, 2017. (doi:10.1016/j.applthermaleng.2017.07.045)

[5] Adibhatla, S., Kaushik, S. C.: Energy, exergy and economic (3E) analysis of integrated solar direct steam generation combined cycle power plant, Sustainable Energy Technologies and Assessments 20, p. 88-97, 2017. (doi:10.1016/j. seta.2017.01.002)

[6] Esquivel Patino, G. G., Napoles Rivera, F.: Global warming potential and net power output analysis of natural gas combined cycle power plants coupled with $\mathrm{CO}_{2}$ capture systems and organic Rankine cycles, Journal of Cleaner Production 208, p. 11-18, 2019. (doi:10.1016/j.jclepro.2018.10.098)

[7] Lorencin, I., Anđelić, N., Mrzljak, V., Car, Z.: Genetic Algorithm Approach to Design of Multi-Layer Perceptron for Combined Cycle Power Plant Electrical Power Output Estimation, Energies 12 (22), 4352, 2019. (doi:10.3390/en12224352)

[8] Behrendt, C., Stoyanov, R.: Operational characteristic of selected marine turbounits powered by steam from auxiliary oil-fired boilers, New Trends in Production Engineering 1 (1), p. 495-501, 2018. (doi:10.2478/ntpe-2018-0061)

[9] Mrzljak, V., Mrakovčić, T.: Comparison of COGES and dieselelectric ship propulsion systems, Journal of Maritime \& Transportation Sciences-Special edition No. 1, p. 131-148, 2016. (doi:10.18048/2016-00.131)

[10] Hafdhi, F., Khir, T., Ben Yahyia, A., Ben Brahim, A.: Energetic and exergetic analysis of a steam turbine power plant in an existing phosphoric acid factory, Energy Conversion and Management 106, p. 1230-1241, 2015. (doi:10.1016/j.enconman.2015.10.044)

[11] Adibhatla, S., Kaushik, S. C.: Energy, exergy, economic and environmental (4E) analyses of a conceptual solar aided coal fired 500 MWe thermal power plant with thermal energy storage option, Sustainable Energy Technologies and Assessments 21, p. 89-99, 2017. (doi:10.1016/j.seta.2017. 05.002)

[12] Kumar, S., Kumar, D., Memon, R. A., Wassan, M. A., Ali, M. S.: Energy and Exergy Analysis of a Coal Fired Power Plant, Mehran University Research Journal of Engineering \& Technolo- 
gy 37 (4), p. 611-624, 2018. (doi:10.22581/muet1982. 1804.13)

[13] Gao, J., Zhang, Q., Wang, X., Song, D., Liu, W., Liu, W.: Exergy and exergoeconomic analyses with modeling for $\mathrm{CO}_{2}$ allocation of coal-fired CHP plants, Energy 152, p. 562-575, 2018. (doi:10.1016/j.energy.2018.03.171)

[14] Taheri, M. H., Mosaffa, A. H., Garousi Farshi, L.: Energy, exergy and economic assessments of a novel integrated biomass based multigeneration energy system with hydrogen production and LNG regasification cycle, Energy 125, p. 162-177, 2017. (doi:10.1016/j.energy.2017.02.124)

[15] Ahmadi, G., Toghraie, D., Akbari, O. A: Energy, exergy and environmental (3E) analysis of the existing CHP system in a petrochemical plant, Renewable and Sustainable Energy Reviews 99, p. 234-242, 2019. (doi:10.1016/j.rser.2018.10.009)

[16] Lorencin, I., Anđelić, N., Mrzljak, V., Car, Z.: Multilayer Perceptron approach to Condition-Based Maintenance of Marine CODLAG Propulsion System Components, Scientific Journal of Maritime Research 33 (2), p. 181-190, 2019. (doi:10.31217/ p.33.2.8)

[17] Mehrpanahi, A., Naserabad, S. N., Ahmadi, G.: Multi-objective linear regression based optimization of full repowering a single pressure steam power plant, Energy 179, p. 1017-1035, 2019. (doi:10.1016/j.energy.2019.04.208)

[18] Ziółkowski, P., Kowalczyk, T., Lemański, M., Badur, J.: On energy, exergy, and environmental aspects of a combined gassteam cycle for heat and power generation undergoing a process of retrofitting by steam injection, Energy Conversion and Management 192, p. 374-384, 2019. (doi:10.1016/j.enconman.2019.04.033)

[19] Kaushik, S.C., Abhyankar, Y.P., Bose, S. Mohan, S.: Exergoeconomic evaluation of a solar thermal power plant, International Journal of Solar Energy 21 (4), p. 293-314, 2001. (doi:10.1080/01425910108914377)

[20] Mrzljak, V., Poljak, I., Prpić-Oršić, J.: Exergy analysis of the main propulsion steam turbine from marine propulsion plant, Shipbuilding 70 (1), p. 59-77, 2019. (doi:10.21278/ brod70105)

[21] Mrzljak, V., Poljak, I.: Energy Analysis of Main Propulsion Steam Turbine from Conventional LNG Carrier at Three Different Loads, International Journal of Maritime Science \& Technology “Our Sea” 66 (1), p. 10-18, 2019. (doi:10.17818/ $\mathrm{NM} / 2019 / 1.2)$

[22] Hajebzadeh, H., Ansari, A.N.M., Niazi, S.: Mathematical modeling and validation of a 320 MW tangentially fired boiler: A case study, Applied Thermal Engineering 146, p. 232-242, 2019. (doi:10.1016/j.applthermaleng.2018.09.102)

[23] Mrzljak, V., Poljak, I., Medica-Viola, V.: Dual fuel consumption and efficiency of marine steam generators for the propulsion of LNG carrier, Applied Thermal Engineering 119, p. 331346, 2017. (doi:10.1016/j.applthermaleng.2017.03.078)

[24] Zhao, Y., Wang, C., Liu, M., Chong, D., Yan, J.: Improving operational flexibility by regulating extraction steam of high-pressure heaters on a $660 \mathrm{MW}$ supercritical coal-fired power plant: A dynamic simulation, Applied Energy 212, p. 12951309, 2018. (doi:10.1016/j.apenergy.2018.01.017)

[25] Mrzljak, V., Poljak, I., Medica-Viola, V.: Thermodynamic analysis of high-pressure feed water heater in steam propulsion system during exploitation, Shipbuilding 68 (2), p. 45-61, 2017. (doi:10.21278/brod68204)

[26] Kostyuk, A., Frolov, V.: Steam and gas turbines, Mir Publishers, Moscow, 1988.
[27] Sutton, I.: Plant Design and Operations, Elsevier Inc., 2015.

[28] Uysal, C., Kurt, H., Kwak H.-Y.: Exergetic and thermoeconomic analyses of a coal-fired power plant, International Journal of Thermal Sciences 117, p. 106-120, 2017. (doi:10.1016/j.ijthermalsci.2017.03.010)

[29] Adibhatla, S., Kaushik, S.C.: Energy and exergy analysis of a super critical thermal power plant at various load conditions under constant and pure sliding pressure operation, Applied Thermal Engineering 73, p. 49-63, 2014. (doi:10.1016/j.applthermaleng.2014.07.030)

[30] Koroglu, T., Sogut, O.S.: Conventional and Advanced Exergy Analyses of a Marine Steam Power Plant, Energy 163, p. 392403, 2018. (doi:10.1016/j.energy.2018.08.119)

[31] Burin, E.K., Vogel, T., Multhaupt, S., Thelen, A., Oeljeklaus, G., Gorner, K., Bazzo, E.: Thermodynamic and economic evaluation of a solar aided sugarcane bagasse cogeneration power plant, Energy 117, Part 2, p. 416-428, 2016. (doi:10.1016/j. energy.2016.06.071)

[32] Mrzljak, V., Poljak, I., Medica-Viola, V.: Efficiency and losses analysis of low-pressure feed water heater in steam propulsion system during ship manoeuvring period, Scientific Journal of Maritime Research 30, p. 133-140, 2016. (doi: 10.31217/p.30.2.6)

[33] Kamil Mohammed, M., Al Doori, W.H., Jassim, A.H., Ibrahim, T.K., Al-Sammarraie, A.T.: Energy and Exergy Analysis of the Steam Power Plant Based On Effect the Numbers of Feed Water Heater, Journal of Advanced Research in Fluid Mechanics and Thermal Sciences 56 (2), p. 211-222, 2019. (ISSN: 2289-7879)

[34] Medica-Viola, V., Pavković, B., Mrzljak, V.: Numerical model for on-condition monitoring of condenser in coal-fired power plants, International Journal of Heat and Mass Transfer 117, p. 912-923, 2018. (doi:10.1016/j.ijheatmasstransfer.2017. 10.047)

[35] Laskowski, R.: Relations for steam power plant condenser performance in off-design conditions in the function of inlet parameters and those relevant in reference conditions, Applied Thermal Engineering 103, p. 528-536, 2016. (doi: 10.1016/j.applthermaleng.2016.04.127)

[36] Lemmon, E.W., Huber, M.L., McLinden, M.O.: NIST reference fluid thermodynamic and transport properties - REFPROP, version 9.0, User's guide, Colorado, 2010.

[37] Kanoğlu, M., Çengel, Y.A., Dincer, I.: Efficiency Evaluation of Energy Systems, Springer Briefs in Energy, Springer, 2012. (doi:10.1007/978-1-4614-2242-6)

[38] Mrzljak, V., Senčić, T., Žarković, B.: Turbogenerator Steam Turbine Variation in Developed Power: Analysis of Exergy Efficiency and Exergy Destruction Change, Modelling and Simulation in Engineering 2018. (doi:10.1155/2018/2945325)

[39] Noroozian, A., Mohammadi, A., Bidi, M., Ahmadi, M. H.: Energy, exergy and economic analyses of a novel system to recover waste heat and water in steam power plants, Energy Conversion and Management 144, p. 351-360, 2017. (doi:10.1016/j.enconman.2017.04.067)

[40] Cengel Y., Boles M.: Thermodynamics an engineering approach, Eighth edition, McGraw-Hill Education, 2015.

[41] Mrzljak, V.: Low power steam turbine energy efficiency and losses during the developed power variation, Technical Journal 12 (3), p. 174-180, 2018. (doi:10.31803/tg20180201002943)

[42] Mitrović, D., Živković, D., Laković, M.S.: Energy and Exergy Analysis of a 348.5 MW Steam Power Plant, Energy Sources, 
Part A, 32, p. 1016-1027, 2010. (doi:10.1080/ 15567030903097012)

[43] Mrzljak, V., Poljak, I., Mrakovčić, T.: Energy and exergy analysis of the turbo-generators and steam turbine for the main feed water pump drive on LNG carrier, Energy Conversion and Management 140, p. 307-323, 2017. (doi:10.1016/j.enconman.2017.03.007)

[44] Moran M., Shapiro H., Boettner, D. D., Bailey, M. B.: Fundamentals of engineering thermodynamics, Seventh edition, John Wiley and Sons, Inc., 2011.

[45] Ahmadi, G. R., Toghraie, D.: Energy and exergy analysis of Montazeri Steam Power Plant in Iran, Renewable and Sustainable Energy Reviews 56, p. 454-463, 2016. (doi:10.1016/j. rser.2015.11.074)

[46] Aljundi, I. H.: Energy and exergy analysis of a steam power plant in Jordan, Applied Thermal Engineering 29, p. 324328, 2009. (doi:10.1016/j.applthermaleng.2008.02.029)

[47] Mrzljak, V., Prpić-Oršić, J., Senčić, T.: Change in Steam Generators Main and Auxiliary Energy Flow Streams During the Load Increase of LNG Carrier Steam Propulsion System, Scientific Journal of Maritime Research 32 (1), p. 121-131, 2018. (doi:10.31217/p.32.1.15)
[48] Erdem, H.H., Akkaya, A.V., Cetin, B., Dagdas, A., Sevilgen, S.H., Sahin, B., Teke, I., Gungor, C., Atas, S.: Comparative energetic and exergetic performance analyses for coal-fired thermal power plants in Turkey, International Journal of Thermal Sciences 48, p. 2179-2186, 2009. (doi:10.1016/j.ijthemalsci.2009.03.007)

[49] Baldi, F., Ahlgren, F., Van Nguyen, T., Thern, M., Andersson, K.: Energy and Exergy Analysis of a Cruise Ship, Energies 11, 2508, 2018. (doi:10.3390/en11102508)

[50] Mrzljak, V., Blecich, P., Anđelić, N., Lorencin, I.: Energy and Exergy Analyses of Forced Draft Fan for Marine Steam Propulsion System during Load Change, Journal of Marine Science and Engineering 7, 381, 2019. (doi:10.3390jmse7110381)

[51] Lorencin, I., Anđelić, N., Mrzljak, V., Car, Z.: Exergy analysis of marine steam turbine labyrinth (gland) seals, Scientific Journal of Maritime Research 33 (1), p. 76-83, 2019. (doi: 10.31217/p.33.1.8)

[52] Blažević, S., Mrzljak, V., Anđelić, N., Car, Z.: Comparison of energy flow stream and isentropic method for steam turbine energy analysis, Acta Polytechnica 59 (2), p. 109-125, 2019. (doi:10.14311/AP.2019.59.0109)

[53] Elčić, Z.: Steam turbines, ABB, Karlovac, National and University Library Zagreb, 1995. 